\title{
microRNAs in the Lymphatic Endothelium: Master Regulators of Lineage Plasticity and Inflammation
}

\author{
Daniel Yee, Mark C. Coles and Dimitris Lagos* \\ Centre for Immunology and Infection, Department of Biology, Hull York Medical School, University of York, York, UK
}

OPEN ACCESS

Edited by:

Silvia Della Bella,

University of Milan, Italy

Reviewed by:

Neha Dixit,

DiscoveRx, USA

Kiyoshi Hirahara,

Chiba University, Japan

${ }^{*}$ Correspondence:

Dimitris Lagos

dimitris.lagos@york.ac.uk

Specialty section:

This article was submitted to

Inflammation,

a section of the journal

Frontiers in Immunology

Received: 14 October 2016

Accepted: 20 January 2017

Published: 09 February 2017

Citation:

Yee D, Coles MC and Lagos D (2017)

microRNAs in the Lymphatic

Endothelium: Master Regulators of

Lineage Plasticity and Inflammation.

Front. Immunol. 8:104.

doi: 10.3389/fimmu.2017.00104
microRNAs (miRNAs) are highly conserved, small non-coding RNAs that regulate gene expression at the posttranscriptional level. They have crucial roles in organismal development, homeostasis, and cellular responses to pathological stress. The lymphatic system is a large vascular network that actively regulates the immune response through antigen trafficking, cytokine secretion, and inducing peripheral tolerance. Here, we review the role of miRNAs in the lymphatic endothelium with a particular focus on their role in lymphatic endothelial cell (LEC) plasticity, inflammation, and regulatory function. We highlight the lineage plasticity of LECs during inflammation and the importance of understanding the regulatory role of miRNAs in these processes. We propose that targeting miRNA expression in lymphatic endothelium can be a novel strategy in treating human pathologies associated with lymphatic dysfunction.

Keywords: lymphatic endothelial cells, microRNA, inflammation, lineage plasticity, lymphangiogenesis

\section{INTRODUCTION}

The lymphatic system is a transport network that regulates tissue fluid homeostasis, the absorption of macromolecules, and the trafficking of immune cells (1). Lymphatic vessels are made up of a single layer of partly overlapping lymphatic endothelial cells (LECs). Embryonic studies on development of lymphatic vasculature have identified key transcription factors required for development and maintenance of the lymphatic system. The same transcription factors regulate lymphangiogenesis, the process of new lymphatic vessel growth from pre-existing vessels, which has crucial roles in wound healing, inflammation, infection, and cancer. In addition to transcriptional regulation, posttranscriptional mechanisms play a key role in LEC responses to inflammation. In particular, several microRNAs (miRNAs) have emerged as key determinants of LEC differentiation and inflammatory responses. This review will discuss our current understanding of the role of individual miRNAs and components of the miRNA biogenesis machinery in LEC immune function.

\section{miRNA-MEDIATED SILENCING}

microRNAs are a class of highly conserved, small non-coding RNA ( 20-24 nt) that regulate gene expression at the posttranscriptional level of all biological pathways including cell development, differentiation, and function (2). In mammals, the canonical process of miRNA biogenesis encompasses 
the generation of primary miRNA (pri-miRNA) transcripts that are transcribed by RNA polymerase II in the nucleus. Stem-loop structures of pri-miRNA transcripts are processed by the RNAse III endonuclease, Drosha, to form hairpin-shaped precursor miRNA (pre-miRNA) $(3,4)$. Following this, pre-miRNA is exported into the cytoplasm where it is further processed by another RNAse III endonuclease, Dicer, which cleaves off the hairpin structure. The resultant double-stranded miRNA is separated into two strands with the mature miRNA strand packaged onto the miRNA-induced silencing complex that includes an Argonaute (AGO) effector protein. The miRNA guides RISC to specific target sites, primarily the $3^{\prime}$ untranslated region (UTR) of target mRNAs, leading to repression of target gene expression (5). Binding sites are generally 8 mers or canonical sites that enable high miRNA regulation of mRNA expression (6). Due to this short target sequence, miRNAs can have multiple targets, and it is predicted that $30 \%$ of all protein-coding genes is under miRNA regulation in mammals (7).

\section{EMBRYONIC DEVELOPMENT AND SPECIFICATION OF THE LYMPHATIC VASCULATURE}

Sabin hypothesized the venous origin of the lymphatic system (8), which became increasingly supported by developmental studies around the beginning of the twenty-first century (9). Specific genes for lymphatic differentiation and identity were identified, and these included vascular endothelial growth factor receptor-3 (VEGFR-3), lymphatic vessel hyaluronan receptor-1 (LYVE-1), podoplanin, and prospero-related homeodomain protein 1 (PROX1) (10). VEGFR-3 is a receptor tyrosine kinase for lymphatic-specific VEGF-C and VEGF-D (11). LYVE-1 is a widely used lymphatic-specific marker, implicated in cellular trafficking and a homolog of the CD44 glycoprotein (12, 13). Both VEGFR-3 and LYVE-1 are expressed during early endothelial cell development and become restricted to LECs at later stages. Genetic deletion of VEGFR-3 or VEGF-C in mice leads to defective lymphatic vascular development $(14,15)$. In contrast, LYVE-1 gene-deficient mice develop normal lymphatic vasculature (16).

The murinelymphatic system begins to form in a subpopulation of venous endothelial cells, LEC precursors, at embryonic day (E) 8.5 that express PROX1, LYVE-1, and VEGFR-3 (14). At E9.75, a lymphatic bias signal upregulates PROX1, LEC budding, and formation of primary lymph sacs (10). PROX1-deficient embryos lack lymphatic vasculature, VEGFR-3, or LYVE-1 expression and are embryonic lethal at E14.5 (10). Two upstream transcriptional regulators of PROX1, SOX18 (17), and COUP-TFII promote the lymphatic bias signal until E13.5 $(18,19)$. PROX1 and VEGFR-3 continue to be expressed only in postnatal and adult lymphatic vasculature (20). Constant levels of PROX1 are required to maintain LEC lineage, which is supported by VEGF-C/VEGFR-3 signaling (21). Postnatal LECs have lower PROX1 expression compared with embryonic lymphatic endothelium, suggesting low expression of PROX1 is sufficient to maintain LEC identity (22). Additional transcription factors and regulators of lymphatic development have been reported, including neuropilin $2(23,24)$, FOXC2 $(25,26)$, integrin- $9 \alpha(27,28), \operatorname{NOTCH}(29,30), \mathrm{C}-\mathrm{MAF}$ (31), and GATA2 (32).

\section{miRNAs AND ENDOTHELIAL CELL DEVELOPMENT}

microRNA biogenesis is essential for vertebrate development, and tissue-specificity of miRNAs has been demonstrated in angiogenesis (33-36). Loss of Dicer in mice leads to poor vascular formation and embryonic lethality (33). The highest expressed miRNA in endothelial cells, miR-126 mediates angiogenesis and maintenance of vascular integrity (37-40). Deletion of miR-126 results in vascular leakage, hemorrhaging, and embryonic lethality in a subset of mice (38). Surviving mice lived to adulthood without noticeable abnormalities, suggesting additional regulatory factors after birth. Accordingly, miR-126 targets sprout-related protein-1 (SPRED-1), phosphoinositol-3 kinase regulatory subunit 2 (PIK3R2 also known as P85 $\beta$ ), and VCAM-1 in human and murine cells (37-39). By targeting VCAM-1, miR-126 can inhibit leukocyte adherence and potentially regulate vascular inflammation (37). SPRED-1 is an intracellular inhibitor of angiogenic and MAP kinase signaling, and its repression by miR-126 correlated with the increase of pro-angiogenic genes VEGF and fibroblast growth factor in mice (38). Additionally, VEGF can induce miR132 and promote angiogenesis by suppressing p120RasGAP in human vascular endothelial cells (41).

\section{REGULATION OF THE MIRNA BIOGENESIS MACHINERY IN LECs}

In addition to individual miRNAs, the miRNA biogenesis machinery is regulated during activation of LECs. AGO2 levels are controlled by miR-132 in human LECs (42). Inhibition of miR-132 in activated LECs results in increased AGO2 and the anti-angiogenic miR-221, providing further support for the function of miR-132 in endothelium. Furthermore, activation of TIE-2 by angiopoietin-1 (ANG-1) results in phosphorylation of TRBP (43), a DICER co-factor, which facilitates miRNA processing (44). Through this mechanism, ANG-1 treatment increases levels of miRNAs, including miR-126 and miR-21, which could contribute to the antiapoptotic function of ANG-1 $(45,46)$ in LECs.

\section{LEC PLASTICITY}

Altering the levels of PROX1 expression during embryonic, postnatal, or adult stages can reprogram LEC phenotype into blood endothelial cell (BEC) $(28,47,48)$. PROX1 deletion results in the upregulation of BEC-specific markers in human and murine LECs (47). Conversely, BECs can be transcriptionally reprogramed by overexpression of PROX1 in vitro, resulting in upregulation of VEGFR-3 and podoplanin and suppression of BEC-specific transcripts, such as the transcription factor STAT6 $(48,49)$. These studies represent that endothelial cell differentiation is reversible and highlight the plasticity of LECs. 


\section{miRNAs AND LEC LINEAGE COMMITMENT}

The 3'-UTR of PROX1 is remarkably long ( $5.4 \mathrm{~kb}$ ) and conserved among vertebrates (50), which suggests PROX1 expression may be posttranscriptionally regulated by miRNAs. In contrast, the $3^{\prime}$ UTR length of SOX18 (585 bp) is short and likely to have less miRNA regulation. Profiling of miRNAs in human LECs and BECs led to the discovery that lymphatic development can be regulated by BEC miRNA signatures (40). Overexpression of miR-31 was shown to repress FOXC2 and several other LECsignature genes (40). Both miR-31 and miR-181a can target PROX1 and as a result repress LEC-specific genes, including VEGFR-3, and vascular development in embryonic LECs (22, 40). Furthermore, signaling from bone morphogenetic protein (BMP) 2, a member of the TGF- $\beta$ family, inhibited Prox-1 expression and lymphatic differentiation during zebrafish and murine development (51). Interestingly, BMP2 signaling upregulated miRNAs: miR-194, miR-186, miR-99a, miR-92a and also miR-31, and miR-181a (51). Knockdown of SMAD4 by siRNA downregulated the expression of miR-31 and miR-181a indicating a possible involvement of BMP2 as a negative regulator of LEC identity (51). Recently, miR-466 was shown to suppress PROX1 expression and tube formation in human dermal LECs, and both miR-466 and miR-181a induced inhibition of corneal lymphangiogenesis in rats (52).

\section{LECs IN INFLAMMATION AND LYMPHANGIOGENESIS}

The lymphatic vessels serve as a conduit for transport of leukocytes and antigen-presenting cells to lymph nodes (LNs), which orchestrate initiation of adaptive immune response (11). LECs express the chemokine ligand, CCL21 that attracts and guides the interactions of CCR7-positive T, B, and dendritic cells (DCs) to LNs via the afferent lymphatics (53). Not all LECs are equal, reportedly, LN-LECs express different levels of CCL21 forming chemokine gradients that facilitate directional migration into the LNs through an atypical chemokine receptor, CCRL1 (54). The role of LECs in immune regulation has been demonstrated in a series of papers showing LECs contributing to the induction of peripheral tolerance of DC and T cells. In human LECs, tumor necrosis factor alpha (TNF $\alpha$ ) induces vascular and intercellular cell adhesion molecule 1 (VCAM-1, ICAM-1) and E-selectin, facilitating adherence of DCs to the endothelium (55). TNF $\alpha$-stimulated lymphatic endothelium can interact with DCs via cell-to-cell contact to suppress human DC maturation and function by an ICAM-1-Mac-1 (CD11b) interaction (56). Notably, murine LECs lack expression of co-stimulatory ligands but can express the inhibitory checkpoint ligand, programed cell death ligand-1 (PD-L1) to negatively regulate $\mathrm{CD} 8^{+} \mathrm{T}$ cells $(57-60)$. LECs can also express MHC II in vivo and may induce tolerance of $\mathrm{CD}^{+}$ and $\mathrm{CD} 8^{+} \mathrm{T}$ cells either by acting as an antigen reservoir for DCs or through cross-presentation of antigens (60-64). The mechanism of antigen transfer from LEC to DCs and whether
LECs can induce similar levels of tolerance as DCs remains to be further understood.

During inflammation, the lymphatic system becomes activated and lymphatic remodeling is induced in both peripheral tissues and the draining LN (65). The increase in lymphangiogenesis may aid in the resolution of inflammation. Inflammation-induced lymphangiogenesis is commonly regulated by pathways involving VEGF-C/VEGFR-3 and VEGF-A/VEGFR-2 signaling (11). Studies in mice demonstrated that lymphangiogenesis is driven by increased VEGF-C, VEGF-D, and VEGF-A from macrophages during acute skin inflammation and chronic airway infection, reported to promote antigen clearance and prevent lymphedema $(66,67)$. Lymphatic vessels are impaired during chronic skin inflammation, which can be alleviated by the overexpression of VEGF-C (68). Interestingly, VEGF-C stimulation in skin inflammation instigated LECs to produce anti-inflammatory prostaglandin synthase, which led to higher levels of IL-10 on DCs leading to suppressed DC maturation (69). B cells can enhance the growth of LN lymphatic vasculature through VEGF secretion and increase DC migration to the LN (70). However, interferon-gamma (IFN- $\gamma$ ) secretion from $\mathrm{T}$ cells suppressed growth of LN-lymphatic vasculature in vivo and downregulated the expression of PROX1, LYVE-1, and podoplanin in vitro in a JAK/STAT-dependent mechanism (71). IFN- $\gamma$ knockout mice express a higher baseline of lymphatic vasculature in the LN. Expression of PROX1, VEGFR-3, and LYVE-1 are also downregulated during acute skin inflammation $(72,73)$. In human dermal LECs, transforming growth factor- $\beta$ (TGF- $\beta$ ) or TNF $\alpha$ stimulation results in loss of PROX1 and LYVE-1 expression $(74,75)$. In contrast, studies in mice suggest that NF- $\mathrm{kB}$ induces PROX1 and VEGFR-3 in a lipopolysaccharide (LPS)-induced peritonitis model, increasing sensitivity of pre-existing lymphatic vessels to VEGF-C and VEGF-D-expressing leukocytes (76). Additionally, IL-3 in LECs can induce PROX1 and podoplanin expression and maintain the differentiated LEC phenotype in vitro (77). LECs are also a major source of IL-7 in vivo which is required for remodeling and homeostasis of the $\mathrm{LN}$ microenvironment (78).

\section{miRNAs IN LECs DURING INFLAMMATION AND INFECTION}

Studies have demonstrated miRNAs in the regulation of inflammation including miR-146a/b, miR-155, and miR-132 in both immune and non-immune cell types (79-82). Several activities have been reported for miR-155 across the immune system, including Th1 differentiation of murine $\mathrm{CD} 4^{+} \mathrm{T}$ cells by inhibiting IFN- $\gamma$ signaling (83) and production of immunoglobulin class-switch differentiation of $\mathrm{B}$ cells by targeting transcription factor PU.1 (84). A wide range of inflammatory stimuli induce miR-155 expression including LPS, poly (I:C), IFN $-\beta$, and TNF $\alpha$ in human and murine macrophages, monocytes, and endothelial cells $(79,80,85,86)$. In addition, miR- 155 regulates angiogenesis and inflammation by negatively regulating ETS-1, upstream of VCAM-1, and angiotensin II type 1 receptor (87).

microRNA profiling of rat mesenteric LECs treated with $\mathrm{TNF} \alpha$ for 2,24 , and $96 \mathrm{~h}$ indicated a distinct miRNA signature at 
various time points (88). Several miRNAs involved in angiogenesis, endothelial sprouting, and cell migration were upregulated, while miRNAs associated with cell survival and proliferation were downregulated at 24 and/or $96 \mathrm{~h}$. Of those upregulated, miR-9 was shown to directly target NF- $\kappa B$, downstream of TNF $\alpha$ signaling, and regulate $\mathrm{TNF} \alpha$-mediated inflammatory mechanisms. In addition, overexpression of miR-9 increases VEGFR-3 expression and tube formation, indicating a possible role in lymphangiogenesis. VEGFR-3 was also shown to be regulated by a mirtron miR-1236, arising from a spliced-out intron that is processed independently of Drosha, in human LECs (89). IL- $1 \beta$ can induce miR-1236 and downregulate VEGFR-3 protein which is similarly reported in inflammatory lymphangiogenesis. Although miR-1236 is lowly expressed in human LECs, it may be upregulated during inflammation-induced lymphangiogenesis to control the expression of VEGF-C/VEGFR-3 signaling.

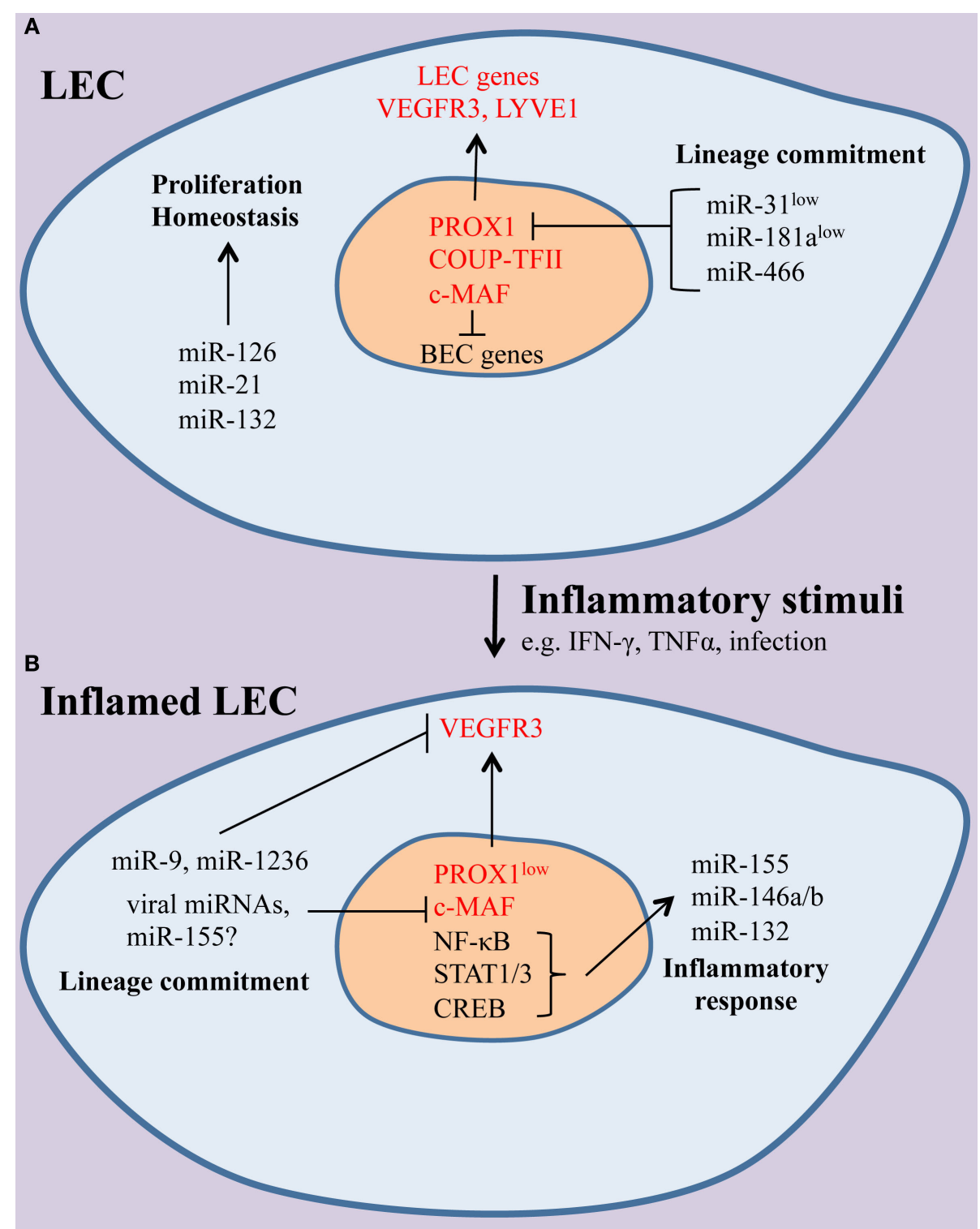

FIGURE 1 The effect of inflammation on the microRNAs (miRNA) landscape of lymphatic endothelial cells (LECs). (A) Under homeostatic conditions, miRNAs, including miR-126, miR-21, and miR-132, contribute to normal LEC function. Lymphatic identity is maintained through suppression of the blood endothelial cell (BEC)-enriched miRNAs miR-31 and miR-181a, which can repress LEC-specific genes, including the master LEC fate regulator PROX1 and the receptor tyrosine kinase vascular endothelial growth factor receptor-3 (VEGFR-3). (B) During inflammation, a set of immunologically active miRNAs (miR-155, miR-132, miR-146a) are induced and shape LEC immune responses. In addition, LEC-specific genes are downregulated and miRNAs, including miR-9, miR-1236, and miR-K12-11, a viral ortholog of miR-155, contribute to the loss of LEC identity. It is likely that other miRNAs may modulate immune gene expression and lineage plasticity in LECs. 


\section{LESSONS FROM KAPOSI'S SARCOMA HERPESVIRUS (KSHV)}

Our understanding of gene regulation in LECs has advanced significantly by studying infectious diseases that directly involve LECs. Kaposi's sarcoma (KS) is a tumor from lymphatic endothelial origin and is the most common cancer in untreated HIV-positive patients (90). KSHV infects both LECs and BECs to induce transcriptional reprograming giving rise to mixed phenotypes of LECs and BECs $(91,92)$. Phenotypically, KS is most similar to LECs and occurs at sites rich in LECs such as skin, LN, and mucosa (92). KSHV infection of human LECs induces an early antiviral miRNA response from miR-132 and miR-146a and inhibition of these miRNAs suppressed viral gene expression (82). Overexpression of miR-132 negatively regulates inflammation by impairing the expression of IFN- $\beta$ and interferon-stimulated gene 15. Upon KSHV infection, miR-132 targets the transcriptional co-activator EP300 and downregulates the interferon response, increasing viral gene expression. In addition, KSHV can influence endothelial cell motility by downregulating the miR-221/ miR-222 cluster and upregulating miR-31 (93). Whether upregulation of miR-31 can regulate PROX1 during KSHV infection is unknown. A KSHV latent gene, kaposin B was found to stabilize PROX1 mRNA and drive lymphatic reprograming of BECs (50). An additional target of KSHV infection is the transcription factor c-MAF, which represses BEC-specific identity in human LECs
$(31,91)$. Downregulation of MAF occurs early and is maintained throughout viral infection. The miR-155 KSHV ortholog, miRK12-11 (94), was shown to regulate MAF in human LECs (31). Interestingly miR-155 has been shown to suppress MAF expression in murine $\mathrm{CD} 4^{+} \mathrm{T}$ cells (95).

\section{CONCLUDING REMARKS AND FUTURE DIRECTIONS}

Our understanding of miRNAs in LEC activation has greatly increased from recent reports but this area remains understudied (Figure 1; Table 1). LEC plasticity is under miRNA regulation that allows the rapid response of lymphatic endothelium to inflammatory and angiogenic stimuli. LECs display heterogeneity, and there are different types of lymphatic vessels and LECs that have organ-specific functions (96). Studying miRNAs in certain types of lymphatic vessels and niches, such as the skin, $\mathrm{LN}$, or subpopulations within these contexts, can introduce new tools to understand the different functions that LECs regulate in these tissues.

Targeting miRNAs such as miR-126, miR-9, and miR-132 (Table 1) presents a novel opportunity to deliver localized therapy for treating disease. This can be either to inhibit or mimic the function of the miRNA. Anti-miR-132 was shown to inhibit angiogenesis and decrease tumor burden in a mouse model of human breast carcinoma (41). Antagonism of miR-122 to treat hepatitis

TABLE 1 | microRNAs (miRNAs) in the lymphatic endothelium.

\begin{tabular}{|c|c|c|c|c|}
\hline miRNA & Primary role & Function and target & Model system & Reference \\
\hline miR-126 & $\begin{array}{l}\text { Angiogenesis } \\
\text { Inflammation }\end{array}$ & $\begin{array}{l}\text { Highest expressed miRNA in endothelial cells, which regulates } \\
\text { angiogenesis through SPRED1 and VCAM-1 }\end{array}$ & Human primary ECs, murine ECs & $\begin{array}{l}\text { Wang et al. (38), } \\
\text { Harris et al. (37), and } \\
\text { Fish et al. (39) }\end{array}$ \\
\hline \multirow[t]{2}{*}{ miR-132 } & Angiogenesis & Acts as an angiogenic switch by targeting p120RasGAP & Human umbilical vein ECs & Anand et al. (41) \\
\hline & Inflammation & Regulates anti-viral immunity through EP300 & $\begin{array}{l}\text { Kaposi's sarcoma herpesvirus } \\
\text { (KSHV)-infected lymphatic }\end{array}$ & Lagos et al. (82) \\
\hline
\end{tabular}

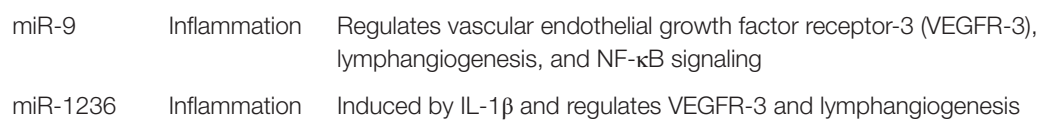

miR-181a Lineage Blood endothelial cell (BEC)-expressed miRNA, which inhibits PROX1 in commitment LEC development

miR-31

Lineage commitment

miR-466 Lineage commitment

miR-K12-6, Lineage miR-K12-11 commitment (ortholog of miR-155)

miR-146a/b Inflammation miR-155 Inflammation Angiogenesis
Angiogenesis Targets transcription factors ETS-2 and ETS-1, respectively, regulating EC motility
BEC-expressed miRNA which inhibits PROX1 and FOXC2 in LEC development

Inhibits PROX1 and tube formation

Viral miRNAs that target c-MAF contributing to virus-induced LEC reprograming

Early-response miRNA involved in TLR4 signaling and innate immunity

Targets ETS-1 upstream of endothelial adhesion molecules such as VCAM-1 endothelial cell (LECS)

Rat LECs and human primary LECs Chakraborty et al. (88)

Cultured human dermal LECs

Murine LECS

Human primary LECs, xenopus, and zebrafish

HDLECs and corneal lymphatic vessels

KSHV-infected LECS

KSHV-infected LECS

Human umbilical vein ECs

Human primary LECs, KSHV-

infected LECs
Lagos et al. (82)

Zhu et al. (87)

Jones et al. (89)

Kazenwadel et al. (22)

Pedrioli et al. (40)

Seo et al. (52)

Hansen et al. (31) and Hong et al. (91)

Wu et al. (93) 
$\mathrm{C}$ virus infection is the first miRNA-targeting therapy in Phase II clinical trials (97). A challenge for miRNA-based therapies is ensuring effective delivery. Targeting miRNAs that drain into the LN through lymphatics vessels can lower the chances of off-target effects, drug resistance, and toxicity $(98,99)$. Lymphatic flow is unidirectional and the vessels can act as a bypass for absorption of compounds, such as lipophilic small molecule drugs, to avoid hepatic first-pass metabolism and enhance bioavailability (100). There are several routes that can be exploited for therapeutic delivery, including mucosal, intestinal, and parenteral (101). The lymphatic system is also thought to link the brain and the immune system (102). Although, lymphatic drug delivery is in its infancy, this approach may serve as a platform for accurately delivering miRNA-modifying compounds to target sites, providing new therapeutic opportunities for chronic inflammatory diseases.

\section{REFERENCES}

1. Swartz MA. The physiology of the lymphatic system. Adv Drug Deliv Rev (2001) 50(1-2):3-20. doi:10.1016/S0169-409X(01)00150-8

2. O'Connell RM, Rao DS, Chaudhuri AA, Baltimore D. Physiological and pathological roles for microRNAs in the immune system. Nat Rev Immunol (2010) 10(2):111-22. doi:10.1038/nri2708

3. Ameres SL, Zamore PD. Diversifying microRNA sequence and function. Nat Rev Mol Cell Biol (2013) 14(8):475-88. doi:10.1038/nrm3611

4. Ha M, Kim VN. Regulation of microRNA biogenesis. Nat Rev Mol Cell Biol (2014) 15(8):509-24. doi:10.1038/nrm3838

5. Huntzinger E, Izaurralde E. Gene silencing by microRNAs: contributions of translational repression and mRNA decay. Nat Rev Genet (2011) 12(2):99110. doi:10.1038/nrg2936

6. Bartel DP. microRNAs: genomics, biogenesis, mechanism, and function. Cell (2004) 116(2):281-97. doi:10.1016/S0092-8674(04)00045-5

7. Filipowicz W, Bhattacharyya SN, Sonenberg N. Mechanisms of posttranscriptional regulation by microRNAs: are the answers in sight? Nat Rev Genet (2008) 9(2):102-14. doi:10.1038/nrg2290

8. Sabin FR. On the origin of the lymphatic system from the veins and the development of the lymph hearts and thoracic duct in the pig. Am J Anat (1902) 1(3):367-89. doi:10.1002/aja.1000010310

9. Srinivasan RS, Dillard ME, Lagutin OV, Lin FJ, Tsai S, Tsai MJ, et al. Lineage tracing demonstrates the venous origin of the mammalian lymphatic vasculature. Genes Dev (2007) 21(19):2422-32. doi:10.1101/gad.1588407

10. Oliver G. Lymphatic vasculature development. Nat Rev Immunol (2004) 4(1):35-45. doi:10.1038/nri1258

11. Tammela T, Alitalo K. Lymphangiogenesis: molecular mechanisms and future promise. Cell (2010) 140(4):460-76. doi:10.1016/j.cell.2010.01.045

12. Banerji S, Ni J, Wang S-X, Clasper S, Su J, Tammi R, et al. LYVE-1, a new homologue of the \{CD 44 glycoprotein. J Cell Biol (1999) 144(4):789-801. doi:10.1083/jcb.144.4.789

13. Jackson DG. Biology of the lymphatic marker LYVE-1 and applications in research into lymphatic trafficking and lymphangiogenesis. APMIS (2004) 112(7-8):526-38. doi:10.1111/j.1600-0463.2004.apm11207-0811.x

14. Wigle JT, Oliver G. Proxl function is required for the development of the murine lymphatic system. Cell (1999) 98:769-78. doi:10.1016/ S0092-8674(00)81511-1

15. Karkkainen MJ, Haiko P, Sainio K, Partanen J, Taipale J, Petrova TV, et al. Vascular endothelial growth factor $\mathrm{c}$ is required for sprouting of the first lymphatic vessels from embryonic veins. Nat Immunol (2004) 5(1):74-80. doi: $10.1038 /$ ni1013

16. Gale NW, Prevo R, Espinosa J, Ferguson DJ, Dominguez MG, Yancopoulos GD, et al. Normal lymphatic development and function in mice deficient for the lymphatic hyaluronan receptor LYVE-1. Mol Cell Biol (2007) 27(2):595-604. doi:10.1128/MCB.01503-06

17. Francois M, Caprini A, Hosking B, Orsenigo F, Wilhelm D, Browne C, et al. Sox18 induces development of the lymphatic vasculature in mice. Nature (2008) 456(7222):643-7. doi:10.1038/nature07391

\section{AUTHOR CONTRIBUTIONS}

DL, MC, DY conceived, co-wrote, and edited the mini review.

\section{FUNDING}

DL is a Medical Research Council New Investigator Research Grant holder (MR/L008505/1). MC is funded by the Medical Research Council (MR/K021125). Work by the authors has also been supported by the Wellcome Trust (097829 Centre for Chronic Diseases and Disorders institutional strategic support fund; WT095024MA CIDCATS PhD training program). DY is supported by the Biotechnology and Biological Sciences Research Council Doctoral Training Program in "Mechanistic Biology and its Strategic Application" (BB/J01113/1).

18. You LR, Lin FJ, Lee CT, DeMayo FJ, Tsai MJ, Tsai SY. Suppression of notch signalling by the COUP-TFII transcription factor regulates vein identity. Nature (2005) 435(7038):98-104. doi:10.1038/nature03511

19. Srinivasan RS, Geng X, Yang Y, Wang Y, Mukatira S, Studer M, et al. The nuclear hormone receptor Coup-TFII is required for the initiation and early maintenance of Prox 1 expression in lymphatic endothelial cells. Genes Dev (2010) 24:696-707. doi:10.1101/gad.1859310

20. Wigle JT, Harvey N, Detmar M, Lagutina I, Grosveld G, Gunn MD, et al. An essential role for Proxl in the induction of the lymphatic endothelial cell phenotype. EMBO J (2002) 21(7):1505-13. doi:10.1093/emboj/21.7.1505

21. Srinivasan RS, Escobedo N, Yang Y, Interiano A, Dillard ME, Finkelstein D, et al. The Prox1-Vegfr3 feedback loop maintains the identity and the number of lymphatic endothelial cell progenitors. Genes Dev (2014) 28:2175-87. doi:10.1101/gad.216226.113.is

22. Kazenwadel J, Michael MZ, Harvey NL. Proxl expression is negatively regulated by miR-181 in endothelial cells. Blood (2010) 116(13):2395-401. doi:10.1182/blood-2009-12-256297

23. Yuan L, Moyon D, Pardanaud L, Bréant C, Karkkainen MJ, Alitalo K, et al. Abnormal lymphatic vessel development in neuropilin 2 mutant mice. Development (2002) 129(20):4797-806.

24. Xu Y, Yuan L, Mak J, Pardanaud L, Caunt M, Kasman I, et al. Neuropilin-2 mediates VEGF-C-induced lymphatic sprouting together with VEGFR3. J Cell Biol (2010) 188(1):115-30. doi:10.1083/jcb.200903137

25. Petrova TV, Karpanen T, Norrmén C, Mellor R, Tamakoshi T, Finegold $\mathrm{D}$, et al. Defective valves and abnormal mural cell recruitment underlie lymphatic vascular failure in lymphedema distichiasis. Nat Med (2004) 10(9):974-81. doi:10.1038/nm1094

26. Norrmen C, Ivanov KI, Cheng J, Zangger N, Delorenzi M, Jaquet M, et al. FOXC2 controls formation and maturation of lymphatic collecting vessels through cooperation with NFATc1. J Cell Biol (2009) 185(3):439-57. doi:10.1083/jcb.200901104

27. Bazigou E, Xie S, Chen C, Weston A, Miura N, Sorokin L, et al. Integrin- $\alpha 9$ is required for fibronectin matrix assembly during lymphatic valve morphogenesis. Dev Cell (2009) 17(2):175-86. doi:10.1016/j.devcel.2009.06.017

28. Mishima K, Watabe T, Saito A, Yoshimatsu Y, Imaizumi N, Masui S, et al. Proxl induces lymphatic endothelial differentiation via integrin $\alpha 9$ and other signaling cascades. Mol Biol Cell (2007) 18:1421-9. doi:10.1091/ mbc.E06

29. Emuss V, Lagos D, Pizzey A, Gratrix F, Henderson SR, Boshoff C. KSHV manipulates notch signaling by DLL4 and JAG1 to alter cell cycle genes in lymphatic endothelia. PLoS Pathog (2009) 5(10):e1000616. doi:10.1371/ journal.ppat.1000616

30. Kang J, Yoo J, Lee S, Tang W, Aguilar B, Ramu S, et al. An exquisite crosscontrol mechanism among endothelial cell fate regulators directs the plasticity and heterogeneity of lymphatic endothelial cells. Blood (2010) 116(1):140-50. doi:10.1182/blood-2009-11-252270

31. Hansen A, Henderson S, Lagos D, Nikitenko L, Coulter E, Roberts S, et al. KSHV-encoded miRNAs target MAF to induce endothelial cell reprogramming. Genes Dev (2010) 24(2):195-205. doi:10.1101/gad.553410 
32. Kazenwadel J, Betterman KL, Chong CE, Stokes PH, Lee YK, Secker GA, et al. GATA2 is required for lymphatic vessel valve development and maintenance. J Clin Invest (2015) 125(8):2979-94. doi:10.1172/JCI78888

33. Bernstein E, Kim SY, Carmell MA, Murchison EP, Alcorn H, Li MZ, et al. Dicer is essential for mouse development. Nat Genet (2003) 35(3):215-7. doi:10.1038/ng1253

34. Yang WJ, Yang DD, Na S, Sandusky GE, Zhang Q, Zhao G. Dicer is required for embryonic angiogenesis during mouse development. J Biol Chem (2005) 280(10):9330-5. doi:10.1074/jbc.M413394200

35. Kuehbacher A, Urbich C, Zeiher AM, Dimmeler S. Role of dicer and drosha for endothelial microRNA expression and angiogenesis. Circ Res (2007) 101:59-68. doi:10.1161/CIRCRESAHA.107.153916

36. Suárez Y, Fernández-Hernando C, Pober JS, Sessa WC. Dicer dependent microRNAs regulate gene expression and functions in human endothelial cells. Circ Res (2007) 100(8):1164-73. doi:10.1161/01.RES.0000265065. 26744.17

37. Harris TA, Yamakuchi M, Ferlito M, Mendell JT, Lowenstein CJ. microRNA-126 regulates endothelial expression of vascular cell adhesion molecule 1. Proc Natl Acad Sci U S A (2008) 105(5):1516-21. doi:10.1073/pnas.0707493105

38. Wang S, Aurora AB, Johnson BA, Qi X, McAnally J, Hill JA, et al. The endothelial-specific microRNA miR-126 governs vascular integrity and angiogenesis. Dev Cell (2008) 15(2):261-71. doi:10.1016/j.devcel.2008.07.002

39. Fish JE, Santoro MM, Morton SU, Yu S, Yeh RF, Wythe JD, et al. miR-126 regulates angiogenic signaling and vascular integrity. Dev Cell (2008) 15(2):272-84. doi:10.1016/j.devcel.2008.07.008

40. Pedrioli DM, Karpanen T, Dabouras V, Jurisic G, Van De Hoek G, Shin JW, et al. miR-31 functions as a negative regulator of lymphatic vascular lineage-specific differentiation in vitro and vascular development in vivo. Mol Cell Biol (2010) 30(14):3620-34. doi:10.1128/MCB.00185-10

41. Anand S, Majeti BK, Acevedo LM, Murphy EA, Mukthavaram R, Scheppke L, et al. microRNA-132-mediated loss of p120RasGAP activates the endothelium to facilitate pathological angiogenesis. Nat Med (2010) 16(8):909-14. doi: $10.1038 / \mathrm{nm} .2186$

42. Leonov G, Shah K, Yee D, Timmis J, Sharp TV, Lagos D. Suppression of AGO2 by miR-132 as a determinant of miRNA-mediated silencing in human primary endothelial cells. Int J Biochem Cell Biol (2015) 69:75-84. doi:10.1016/ j.biocel.2015.10.006

43. Warner MJ, Bridge KS, Hewitson JP, Hodgkinson MR, Heyam A, Massa $\mathrm{BC}$, et al. S6K2-mediated regulation of TRBP as a determinant of miRNA expression in human primary lymphatic endothelial cells. Nucleic Acids Res (2016) 44(20):9942-55. doi:10.1093/nar/gkw631

44. Heyam A, Lagos D, Plevin M. Dissecting the roles of TRBP and PACT in double-stranded RNA recognition and processing of noncoding RNAs. Wiley Interdiscip Rev RNA (2015) 6(3):271-89. doi:10.1002/wrna.1272

45. Abdel-Malak NA, Srikant CB, Kristof AS, Magder SA, Di Battista JA, Hussain SN. Angiopoietin-1 promotes endothelial cell proliferation and migration through AP-1-dependent autocrine production of interleukin-8. Blood (2008) 111(8):4145-55. doi:10.1182/blood-2007-08-110338

46. Daly C, Wong V, Burova E, Wei Y, Zabski S, Griffiths J, et al. Angiopoietin-1 modulates endothelial cell function and gene expression via the transcription factor FKHR (FOXO1). Genes Dev (2004) 18(9):1060-71. doi:10.1101/ gad.1189704

47. Johnson NC, Dillard ME, Baluk P, Mcdonald DM, Harvey NL, Frase SL, et al. Lymphatic endothelial cell identity is reversible and its maintenance requires Proxl activity. Genes Dev (2008) 22:3282-91. doi:10.1101/ gad.1727208.Despite

48. Petrova TV, Mäkinen T, Mäkelä TP, Saarela J, Virtanen I, Ferrell RE, et al. Lymphatic endothelial reprogramming of vascular endothelial cells by the prox-1 homeobox transcription factor. EMBO J (2002) 21(17):4593-9. doi:10.1093/emboj/cdf470

49. Hong Y-K, Harvey N, Noh Y-H, Schacht V, Hirakawa S, Detmar M, et al. Prox1 is a master control gene in the program specifying lymphatic endothelial cell fate. Dev Dyn (2002) 225(3):351-7. doi:10.1002/ dvdy. 10163

50. Yoo J, Kang J, Lee HN, Aguilar B, Kafka D, Lee S, et al. Kaposin-B enhances the PROX1 mRNA stability during lymphatic reprogramming of vascular endothelial cells by Kaposi's sarcoma herpes virus. PLoS Pathog (2010) 6(8):37-8. doi:10.1371/journal.ppat.1001046
51. Dunworth WP, Cardona-Costa J, Bozkulak EC, Kim JD, Meadows S, Fischer JC, et al. Bone morphogenetic protein 2 signaling negatively modulates lymphatic development in vertebrate embryos. Circ Res (2014) 114(1):56-66. doi:10.1161/CIRCRESAHA.114.302452

52. Seo M, Choi JS, Rho CR, Joo C-K, Lee SK. microRNA miR-466 inhibits lymphangiogenesis by targeting prospero-related homeobox 1 in the alkali burn corneal injury model. J Biomed Sci (2015) 22(1):3. doi:10.1186/ s12929-014-0104-0

53. Förster R, Davalos-Misslitz AC, Rot A. CCR7 and its ligands: balancing immunity and tolerance. Nat Rev Immunol (2008) 8(5):362-71. doi:10.1038/ nri2297

54. Ulvmar MH, Werth K, Braun A, Kelay P, Hub E, Eller K, et al. The atypical chemokine receptor CCRL1 shapes functional CCL21 gradients in lymph nodes. Nat Immunol (2014) 15(7):623-30. doi:10.1038/ni.2889

55. Johnson LA, Clasper S, Holt AP, Lalor PF, Baban D, Jackson DG. An inflammation-induced mechanism for leukocyte transmigration across lymphatic vessel endothelium. J Exp Med (2006) 203(12):2763-77. doi:10.1084/ jem.20051759

56. Podgrabinska S, Kamalu O, Mayer L, Shimaoka M, Snoeck H, Randolph GJ, et al. Inflamed lymphatic endothelium suppresses dendritic cell maturation and function via Mac-1/ICAM-1-dependent mechanism. J Immunol (2009) 183(3):1767-79. doi:10.4049/jimmunol.0802167

57. Cohen JN, Guidi CJ, Tewalt EF, Qiao H, Rouhani SJ, Ruddell A, et al. Lymph node-resident lymphatic endothelial cells mediate peripheral tolerance via aire-independent direct antigen presentation. J Exp Med (2010) 207(4):681-8. doi:10.1084/jem.20092465

58. Tewalt EF, Cohen JN, Rouhani SJ, Engelhard VH. Lymphatic endothelial cells - key players in regulation of tolerance and immunity. Front Immunol (2012) 3:305. doi:10.3389/fimmu.2012.00305

59. Hirosue S, Vokali E, Raghavan VR, Rincon-Restrepo M, Lund AW, Corthésy-Henrioud $\mathrm{P}$, et al. Steady-state antigen scavenging, cross-presentation, and CD8 + T cell priming: a new role for lymphatic endothelial cells. J Immunol (2014) 192(11):5002-11. doi:10.4049/jimmunol. 1302492

60. Rouhani SJ, Eccles JD, Riccardi PJ, Peske D, Tewalt EF, Cohen JN, et al. Roles of lymphatic endothelial cells expressing peripheral tissue antigens in CD4 T-cell tolerance induction. Nat Commun (2015) 6:6771. doi:10.1038/ ncomms7771

61. Lund AW, Duraes FV, Hirosue S, Raghavan VR, Nembrini C, Thomas $\mathrm{SN}$, et al. VEGF-C promotes immune tolerance in B16 melanomas and cross-presentation of tumor antigen by lymph node lymphatics. Cell Rep (2012) 1(3):191-9. doi:10.1016/j.celrep.2012.01.005

62. Nörder M, Gutierrez MG, Zicari S, Cervi E, Caruso A, Guzmán CA. Lymph node-derived lymphatic endothelial cells express functional costimulatory molecules and impair dendritic cell-induced allogenic t-cell proliferation. FASEB J (2012) 26(7):2835-46. doi:10.1096/ff.12205278

63. Dubrot J, Duraes FV, Potin L, Capotosti F, Brighouse D, Suter T, et al. Lymph node stromal cells acquire peptide-MHCII complexes from dendritic cells and induce antigen-specific CD4+ T cell tolerance. J Exp Med (2014) 211(6):1153-66. doi:10.1084/jem.20132000

64. Tamburini BA, Burchill MA, Kedl RM. Antigen capture and archiving by lymphatic endothelial cells following vaccination or viral infection. Nat Commun (2014) 5:3989. doi:10.1038/ncomms4989

65. Kim H, Kataru RP, Koh GY. Inflammation-associated lymphangiogenesis: a double-edged sword? J Clin Invest (2014) 124(3):936-42. doi:10.1172/ JCI71607.936

66. Baluk P, Tammela T, Ator E, Lyubynska N, Achen MG, Hicklin DJ, et al. Pathogenesis of persistent lymphatic vessel hyperplasia in chronic airway inflammation. J Clin Invest (2005) 115(2):247-57. doi:10.1172/ JCI200522037

67. Kataru RP, Jung K, Jang C, Yang H, Schwendener RA, Baik JE, et al. Critical role of $\mathrm{CD} 11 \mathrm{~b}+$ macrophages and VEGF in inflammatory lymphangiogenesis, antigen clearance, and inflammation resolution. Blood (2009) 113(22):5650-9. doi:10.1182/blood-2008-09-176776

68. Huggenberger R, Ullmann S, Proulx ST, Pytowski B, Alitalo K, Detmar M. Stimulation of lymphangiogenesis via VEGFR-3 inhibits chronic skin inflammation. J Exp Med (2010) 207(10):2255-69. doi:10.1084/jem. 20100559 
69. Christiansen AJ, Dieterich LC, Ohs I, Bachmann SB, Bianchi R, Proulx ST, et al. Lymphatic endothelial cells attenuate inflammation via suppression of dendritic cell maturation. Oncotarget (2016) 7(26):39421-35. doi:10.18632/ oncotarget. 9820

70. Angeli V, Ginhoux F, Llodra J, Quemeneur L, Frenette PS, Skobe M, et al. B cell-driven lymphangiogenesis in inflamed lymph nodes enhances dendritic cell mobilization. Immunity (2006) 24(2):203-15. doi:10.1016/ j.immuni.2006.01.003

71. Kataru RP, Kim H, Jang C, Choi DK, Koh BI, Kim M, et al. T lymphocytes negatively regulate lymph node lymphatic vessel formation. Immunity (2011) 34(1):96-107. doi:10.1016/j.immuni.2010.12.016

72. Vigl B, Aebischer D, Nitschke M, Iolyeva M, Rothlin T, Antsiferova O, et al. Tissue inflammation modulates gene expression of lymphatic endothelial cells and dendritic cell migration in a stimulus-dependent manner. Blood (2011) 118(1):205-15. doi:10.1182/blood-2010-12-326447

73. Huggenberger R, Siddiqui SS, Brander D, Ullmann S, Zimmermann K, Antsiferova $\mathrm{M}$, et al. An important role of lymphatic vessel activation in limiting acute inflammation. Blood (2011) 117(17):4667-78. doi:10.1182/ blood-2010-10-316356

74. Johnson LA, Prevo R, Clasper S, Jackson DG. Inflammation-induced uptake and degradation of the lymphatic endothelial hyaluronan receptor LYVE-1. J Biol Chem (2007) 282(46):33671-80. doi:10.1074/jbc.M702889200

75. Oka M, Iwata C, Suzuki HI, Kiyono K, Morishita Y, Watabe T, et al. Inhibition of endogenous TGF-2 signaling enhances lymphangiogenesis. Blood (2008) 111(9):4571-9. doi:10.1182/blood-2007-10-120337

76. Flister MJ, Wilber A, Hall KL, Iwata C, Miyazono K, Nisato RE, et al. Inflammation induces lymphangiogenesis through up-regulation of VEGFR-3 mediated by NF-kB and Prox1. Blood (2010) 115(2):418-29. doi:10.1182/blood-2008-12-196840

77. Gröger M, Loewe R, Holnthoner W, Embacher R, Pillinger M, Herron GS, et al. IL-3 induces expression of lymphatic markers Prox-1 and Podoplanin in human endothelial cells. J Immunol (2004) 173(12):7161-9. doi:10.4049/ jimmunol.173.12.7161

78. Onder L, Narang P, Scandella E, Chai Q, Iolyeva M, Hoorweg K, et al. IL-7producing stromal cells are critical for lymph node remodeling. Blood (2012) 120(24):4675-83. doi:10.1182/blood-2012-03-416859. The

79. Taganov KD, Boldin MP, Chang KJ, Baltimore D. NF-kappaB-dependent induction of microRNA miR-146, an inhibitor targeted to signaling proteins of innate immune responses. Proc Natl Acad Sci US A (2006) 103(33):12481-6. doi:10.1073/pnas.0605298103

80. O'Connell RM, Taganov KD, Boldin MP, Cheng G, Baltimore D. microRNA-155 is induced during the macrophage inflammatory response. Proc Natl Acad Sci U S A (2007) 104(5):1604-9. doi:10.1073/ pnas.0610731104

81. Tili E, Michaille J-J, Cimino A, Costinean S, Dumitru CD, Adair B, et al. Modulation of miR-155 and miR-125b levels following lipopolysaccharide/ TNF-Alpha stimulation and their possible roles in regulating the response to endotoxin shock. J Immunol (2007) 179(8):5082-9. doi:10.4049/jimmunol. 179.8.5082

82. Lagos D, Pollara G, Henderson S, Gratrix F, Fabani M, Milne RSB, et al. miR132 regulates antiviral innate immunity through suppression of the p300 transcriptional co-activator. Nat Cell Biol (2010) 12(5):513-9. doi:10.1038/ ncb2054

83. Banerjee A, Schambach F, DeJong CS, Hammond SM, Reiner SL. MicroRNA-155 inhibits IFN-gamma signaling in CD4+ T cells. Eur J Immunol (2010) 40(1):225-31. doi:10.1002/eji.200939381

84. Vigorito E, Perks KL, Abreu-Goodger C, Bunting S, Xiang Z, Kohlhaas $S$, et al. microRNA-155 regulates the generation of immunoglobulin class-switched plasma cells. Immunity (2007) 27(6):847-59. doi:10.1016/ j.immuni.2007.10.009

85. Suárez Y, Wang C, Manes TD, Pober JS. TNF-induced miRNAs regulate TNF-induced expression of E-Selectin and ICAM-1 on human endothelial cells: feedback control of inflammation. J Immunol (2010) 184(1):21-5. doi:10.4049/jimmunol.0902369.TNF-induced

86. Ruan W, Xu JM, Li SB, Yuan LQ, Dai RP. Effects of down-regulation of microRNA-23a on TNF- $\alpha$-induced endothelial cell apoptosis through caspase-dependent pathways. Cardiovasc Res (2012) 93(4):623-32. doi:10.1093/cvr/cvr290

87. Zhu N, Zhang D, Chen S, Liu X, Lin L, Huang X, et al. Endothelial enriched microRNAs regulate angiotensin II-induced endothelial inflammation and migration. Atherosclerosis (2011) 215(2):286-93. doi:10.1016/ j.atherosclerosis.2010.12.024

88. Chakraborty S, Zawieja DC, Davis MJ, Muthuchamy M. microRNA signature of inflamed lymphatic endothelium and role of miR-9 in lymphangiogenesis and inflammation. Am J Physiol Cell Physiol (2015) 309(10):C680-92. doi:10.1152/ajpcell.00122.2015

89. Jones D, Li Y, He Y, Xu Z, Chen H, Min W. Mirtron microRNA-1236 inhibits VEGFR-3 signaling during inflammatory lymphangiogenesis. Arterioscler Thromb Vasc Biol (2012) 32(3):633-42. doi:10.1161/ATVBAHA. 111.243576

90. Cancian L, Hansen A, Boshoff C. Cellular origin of Kaposi's sarcoma and Kaposi's sarcoma-associated herpesvirus-induced cell reprogramming. Trends Cell Biol (2013) 23(9):421-32. doi:10.1016/j.tcb.2013.04.001

91. Hong YK, Foreman K, Shin JW, Hirakawa S, Curry CL, Sage DR, et al. Lymphatic reprogramming of blood vascular endothelium by Kaposi sarcoma-associated herpesvirus. Nat Genet (2004) 36(7):683-5. doi:10.1038/ ng1383

92. Wang HW, Trotter MW, Lagos D, Bourboulia D, Henderson S, Mäkinen T, et al. Kaposi sarcoma herpesvirus-induced cellular reprogramming contributes to the lymphatic endothelial gene expression in Kaposi sarcoma. Nat Genet (2004) 36(7):687-93. doi:10.1038/ng1384

93. Wu YH, Hu TF, Chen YC, Tsai YN, Tsai YH, Cheng CC, et al. The manipulation of miRNA-gene regulatory networks by KSHV induces endothelial cell motility. Blood (2011) 118(10):2896-905. doi:10.1182/blood-201101-330589

94. Gottwein E, Mukherjee N, Sachse C, Frenzel C, Majoros WH, Chi J-TA, et al. A viral microRNA functions as an orthologue of cellular miR-155. Nature (2007) 450(7172):1096-9. doi:10.1038/nature05992

95. Rodriguez A, Vigorito E, Clare S, Warren MV, Couttet P, Soond DR, et al. Requirement of bic/microRNA-155 for normal immune function. Science (2007) 981:608-11. doi:10.1126/science.1139253

96. Ulvmar MH, Mäkinen T. Heterogeneity in the lymphatic vascular system and its origin. Cardiovasc Res (2016) 111(4):310-21. doi:10.1093/cvr/cvw175

97. Janssen HL, Reesink HW, Lawitz EJ, Zeuzem S, Rodriguez-Torres M, Patel $\mathrm{K}$, et al. Treatment of HCV infection by targeting microRNA. N Engl J Med (2013) 368(18):1685-94. doi:10.1056/NEJMoa1209026

98. Khan AA, Mudassir J, Mohtar N, Darwis Y. Advanced drug delivery to the lymphatic system: lipid-based nanoformulations. Int J Nanomedicine (2013) 8:2733-44. doi:10.2147/IJN.S41521

99. Li Z, Rana TM. Therapeutic targeting of microRNAs: current status and future challenges. Nat Rev Drug Discov (2014) 13(8):622-38. doi:10.1038/ nrd4359

100. Yanez JA, Wang SW, Knemeyer IW, Wirth MA, Alton KB. Intestinal lymphatic transport for drug delivery. Adv Drug Deliv Rev (2011) 63(10-11):923-42. doi:10.1016/j.addr.2011.05.019

101. Trevaskis NL, Kaminskas LM, Porter CJ. From sewer to saviour - targeting the lymphatic system to promote drug exposure and activity. Nat Rev Drug Discov (2015) 14(11):781-803. doi:10.1038/nrd4608

102. Louveau A, Smirnov I, Keyes TJ, Eccles JD, Rouhani SJ, Peske JD, et al. Structural and functional features of central nervous system lymphatic vessels. Nature (2015) 523(7560):337-41. doi:10.1038/nature14432

Conflict of Interest Statement: The authors declare that the research was conducted in the absence of any commercial or financial relationships that could be construed as a potential conflict of interest.

Copyright (c) 2017 Yee, Coles and Lagos. This is an open-access article distributed under the terms of the Creative Commons Attribution License (CC BY). The use, distribution or reproduction in other forums is permitted, provided the original author(s) or licensor are credited and that the original publication in this journal is cited, in accordance with accepted academic practice. No use, distribution or reproduction is permitted which does not comply with these terms. 